\title{
STUDY ON STRESS DISTRIBUTION NEAR CRACK TIP IN BERYLLIUM
}

\section{COMPACT TENSION SPECIMEN}

\author{
Dong Ping ${ }^{1}$, Zhang Pengcheng ${ }^{1}$, Li Ruiwen ${ }^{2}$ \\ ${ }^{1}$ National Key Laboratory Surface Physics and Chemistry, Mianyang, P.R.China \\ ${ }^{2}$ China Academy of Engineering and Physics, Mianyang, P.R.China
}

\begin{abstract}
In order to evaluate the fracture characteristic near the crack tip of beryllium specimen, beryllium compact tension specimen with plane strain state is designed. The stress distribution near the crack tip is measured at diffrent loading level by X3000 stress analyzer. Moreover, the stress and strain fields in beryllium compact tension specimen are calculated by finite element method(FEM). The results show that they are basically identical, except the calculated stress is a bit larger than the measured stress near the crack tip. According to the critical loading of beryllium specimen, the maxium stress and the radius of plasitic zone near the crack tip are calculated by FEM, and the fracture toughness of beryllium is also determined.
\end{abstract}

\section{Introduction}

Beryllium has been identified as a good candidate as a plasma-facing material in the international thermonuclear experiment reactor (ITER). Its low atomic number, high thermal conductivity, and high strength properties are important characteristics of beryllium for this application. However, the ductility of beryllium is low, some micro-cracks and stress must be inevitable produced in beryllium after machining and welding process. If stress in beryllium is large up to some extent, these microcracks will extend to macrocrack, so studying on the stress distribution in beryllium has become more and more interesting for many reseachers. Ravi etc. ${ }^{[1]}$ has measured the stress distribution in hot pressed beryllium specimens under different loading by using neutron diffraction method, which indicateded that anisotropy existes in hot pressed beryllium, and anomalous crack will extend if the loading applying in beryllium specimen exceeds the fracture strength. Zhang Pengcheng etc. ${ }^{[2,3]}$ has studied the machining damage and stress distribuition in beryllium specimens, which showed that many microcracks and twin-crystal exist in surface layer of beryllium after machining, moreover, the damage layer can be eliminated by using chemical etching, at the same time, the stress in the surface layer of beryllium can be relieved at some extent. We have ever studied the welding stress in beryllium extensively ${ }^{[4,5]}$, which showed that a large tension stress existed near the weld seam, moreover, the structure and mechanics state of beryllium specimen are very close to the compact tension specimen when microcracks and voids are located at the root of the welding seam. In order to understand the microfracture characteristic near crack tip and evaluate reliability of welding joint with complicated stress state for beryllium specimens, it is necessary to study stress distribution and evolution in beryllium compact tension specimens.

In this paper, beryllium compact tension specimen with plane strain state is desiged. Beryllium specimen is loaded by using horizontal tension test machine, then the stress distribution near crack tip is measured by using X3000 stress analyzer. At the same time, the stress and strain in beryllium specimen are calculated by finite element method (FEM), which is compared to the measured value. According to the critical loading of beryllium specimen, the maxium stress and the radius of plastic zone at crack tip are calculated by FEM, and the fracture toughness of beryllium is also determined. 


\section{Experimental Procedure}

\subsection{Material and Specimen}

Since the triaxial degree (the ratio of mean stress $\sigma_{\mathrm{m}}$ and equivalent stress $\sigma_{\mathrm{e}}$ ) at crack tip with plane strain state is the highest restrcition under all stress condition, specimen structure and dimension must be required to design as plane strain state when fracture toughness is needed to study. Considering determination of fracture toughness of beryllium, beryllium specimen is designed as the national standard of fracture toughness. The structure and dimension of beryllium specimen is shown in Fig.1, which is made from hot isostatic pressed beryllium wafer.
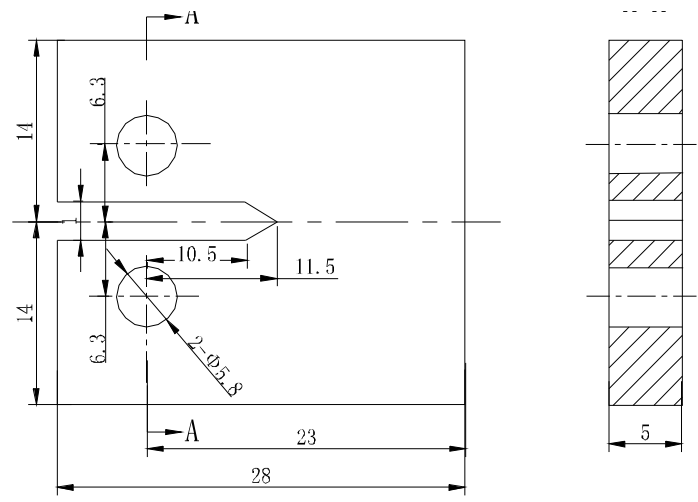

Fig.1 Structure and dimension of CT beryllium specimen

\subsection{Loading and stress measurement at crack tip}

Considering to measure stress distribution near crack tip feasible, beryllium specimen is loaded by using horizontal tension test machine. After beryllium specimen is fixed at the tension test machine using special clamp, the stress distribution near crack tip is measured firstly, then the crossbeam of tension test machine is adjusted by the software controlling tension test machine in order to increase beryllium specimen loading. Once the loading reached to $200 \mathrm{~N}$ and $500 \mathrm{~N}$, respectively, stopping and keeping the loading, the stress distribution near crack tip is measured by X3000 stress analyzer. The distance from the crack tip to the measured point is $0 \mathrm{~mm}, 0.5 \mathrm{~mm}, 1.0 \mathrm{~mm}$, $1.5 \mathrm{~mm}, 2.5 \mathrm{~mm}, 3.5 \mathrm{~mm}, 5.0 \mathrm{~mm}$ and $7.0 \mathrm{~mm}$. In order to ensure the measured result reproduced, the stress at every point is measured twice at the same loading.

A new modified $\psi$ goniometer is adopted in
X3000 stress analyzer. The X-ray stress measure ment parameters are listed as follows: $\mathrm{FeK}_{\alpha}$, $\mathrm{Be}(103)$ plane, diffraction angle $2 \theta$ is $142.3^{\circ}$, the collometer diameter is $1 \mathrm{~mm}$. A free-stress $\mathrm{Ni}$ powder sample is selected for calibration. Multiple exposure mode and the tilt angles $\psi$ are selected as $0, \pm 24.09^{\circ}, \pm 35.26^{\circ}$ and $\pm 45^{\circ}$, respectively.

Exposure time is $3 \mathrm{~s}$, the $\mathrm{X}$-ray voltage is $27 \mathrm{kV}$ and the current is $5.8 \mathrm{~mA}$.

After X-ray stress measuurement, unloading the loading, an axial-deformation measured devices is installed beside the gap of beryllium specimen. Loading beryllim specimen to crack by software controlling tension test machine, and the curve between the loading \& deformation of beryllium specimen is recorded by computer automatically.

\section{Finite Element models}

\subsection{Finite element mesh}

The commercial finite element code ANSY is adopted in this paper. Since the symmetry of beryllium specimen, 1/2 model is used in finite element calculation. The finite element mesh is shown in Fig.2, and a eight-node plane strain element with element No. Plane 82 is adopted. Since the stress singularity at crack tip in the loading exists, a special $1 / 4$ point element is adopted near crack tip, which is suit to solve the stress singularity at crack tip in fracture mechanics. The finite element model has 18753 nodes and 6134 elements.

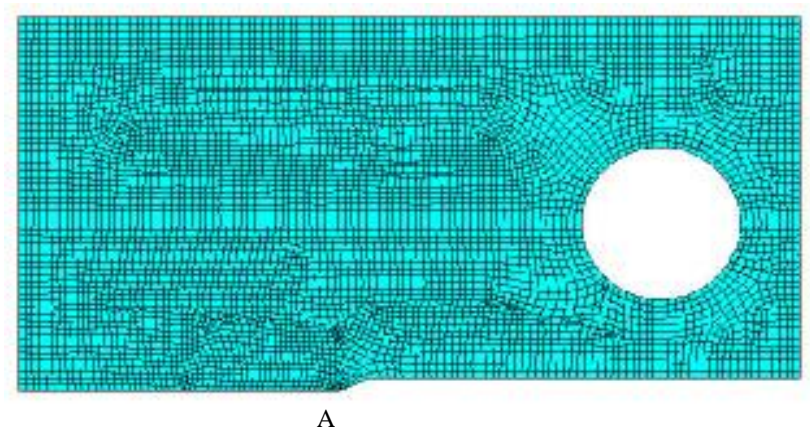

Fig.2 Element mesh figure of FEM

\subsection{Material properties \& boundary conditions}

Young's modulus and poisson's ratio of Be are $324 \mathrm{GPa}$ and 0.025 , and Mises yield criterion with bilinear strength is adopted in the finite element model. The yield strength is $450 \mathrm{MPa}$ and the 
harden modulus is $9.72 \mathrm{GPa}$, which is about 3 percent of ealatic modulus. A symmetry boundary condition is applied from crack tip to the end edge of specimen. The loading is applied as uniform pressure $p$ to outer edge of the round hole, which can be calculated as follows:

$$
p=F / \Phi B
$$

where $F$ is the loading, $\Phi$ is the diameter of round hole, and $B$ is the thickness of the specimen.

Since no transverse displacement normal to the loading direction exists, the vertex of the round hole is restricted in order to avoid the rigid movement. After finite element calculation, a path through crack tip along the crack plane is defined in the ANSYS postprocessor. The stress intensity factor at crack tip is calculated at different loading. From the crtical loading of Be specimen, the fracture toughness of $\mathrm{Be}$ is also determinated.

\section{Results and discussions}

\subsection{Measured stress and comparison of} deformation curve by FEM and experiment

The stress distribution of beryllium specimen at crack tip is shown in Fig.3 at three loading level, where $0 \mathrm{~N}$ is residual stress of beryllium specimen after machining. Since the goniometer diameter is $1 \mathrm{~mm}$, the measured stress stands for the average stress within $1 \mathrm{~mm}$ measured zone acutually. From the figure, the stress concentrate exists at crack tip when no loading is applied, which is about $120 \mathrm{MPa}$. The stress value reduces gradually with increasing the distance between the reference point and crack tip, which is about 0 if the distance is more than $2 \mathrm{~mm}$. The tension stress at crack tip increases rapidly if loading. The maxium tension stress at crack tip is $170 \mathrm{MPa}$ when loading is $200 \mathrm{~N}$, and it becomes $230 \mathrm{MPa}$ when loading is $500 \mathrm{~N}$. Near the edge contrary to the gap of beryllium specimen, the stress is compression, which inceases with increasing the loading.

From the tension test, the curve between the loading \& displacement can be obtained, meantime, it can be also acquired by FEM, which is shown in Fig.4. From the figure, it indicates that they are basically identical, thus the finite element model is verified in this paper.

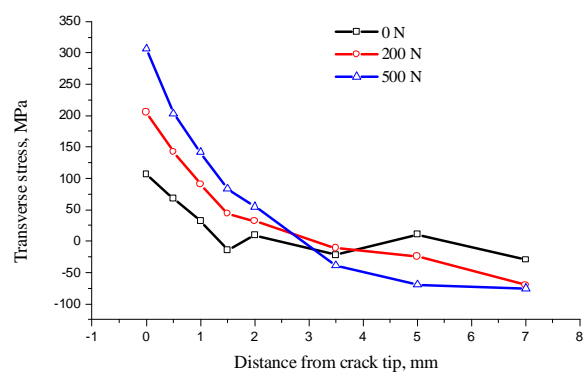

Fig.3 Measured stress value at crack tip of Be specimen

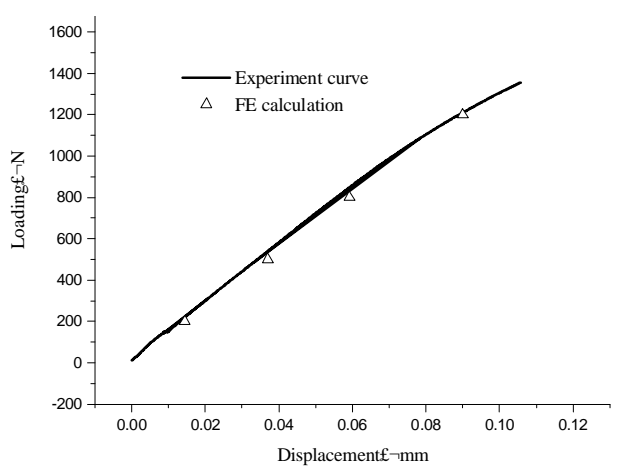

Fig.4 Comparison of loading \& displacement by FEM and experiment

\subsection{Stress distribution near crack tip by FEM}

When the loading is $200 \mathrm{~N}, 500 \mathrm{~N}$ and $1000 \mathrm{~N}$, respectively, the transverse stress near crack tip is shown in Fig.5. From the figure, the stress concentrate exists near crack tip when loading, moreover, this trend becomes more and more evidence with increasing the loading. The maxium transverse stress at crack tip in beryllium specimen is $193 \mathrm{MPa}, 364 \mathrm{MPa}$ and $551 \mathrm{MPa}$ at the above three loading level, respectively. When the loading is greater than $1000 \mathrm{~N}$, plastic deformation will be occur at crack tip. Compression stress is located in beryllium specimen far from the crack tip about $5 \mathrm{~mm}$, which gets more and more with increasing the loading.

When the loading is $500 \mathrm{~N}$, comparsison of stress distribution near crack tip by FEM and X-ray stress measurement is shown in Fig.6, where initial stress from machining has been substracted. We can find that the stress trend is basically identical by FEM and experiment. Near the crack tip, the stress by FEM is larger than that by experiment, which may be resulted from the large stress gradient near crack tip and the large measured zone. 
According to the Fig.4, the critical loading at crack expanding for beryllium specimen is about $1346 \mathrm{~N}$. The plastic strain near crack tip of beryllium specimen at the critical loading by FEM is shown in Fig.7, where the maxium plastic strain near crack tip is about $0.018 \mu \varepsilon$ and the maxium radius of plastic zone is about $0.3 \mathrm{~mm}$.

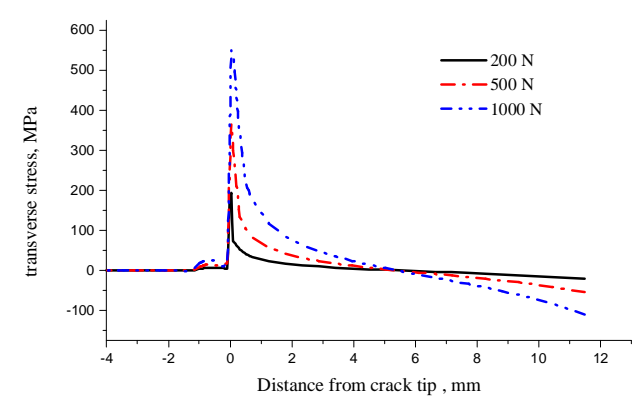

Fig.5 Stress distribution at crack tip of Be specimen

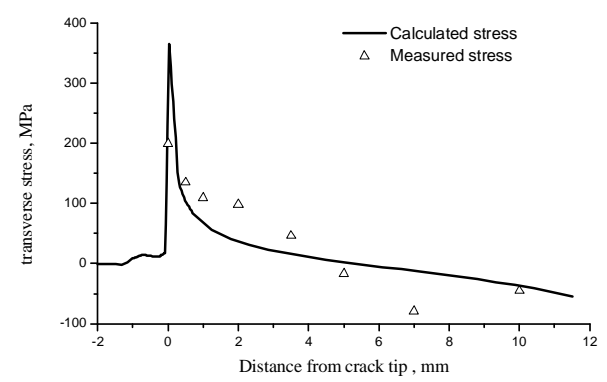

Fig.6 Calculated and measured stress near crack tip at 500N

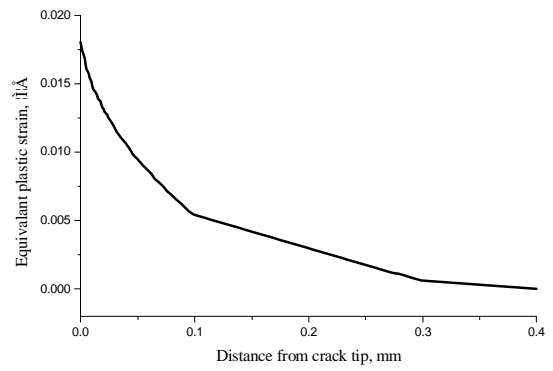

Fig.7 Plastic strain near crack tip at critical loading

3.3 Determiantion of fracture toughness of beryllium

The crack expanding length must be measured exactly if fracture toughness of beryllium is determined directly by experiment. However, the ductility of beryllium is low, and the crack expanding length is very small, so it is difficult to measure the crack expanding length exactly and determine the fracture toughness if the routine method is used. The stress intensity factor at crack

\section{References}

[1]Ravi V, Mark AM, Michael DG. Experimental and numerical determination of strains in beryllium compact tension specimens[R].

LA-UR-97-1140, 1997

[2]Zhang Pengcheng. Study on distribution of machining residual stress for beryllium material [J]. Mining and Metallurgy, tip can be calculated under different loading level by FEM, and the critical loading can be obtained by the tension test when the crack expands. Combined experiement and FEM together, the fracture toughness of beryllium can be acquired indirectly. The relation between the stress intensity factor at crack tip and loading is shown in Fig.8, where the Y-coordinate of the intersection point A between the loading and the curve stands for the fracture toughness of beryllium. From the figure, the fracture toughness of beryllium can be determined, which is about $19.1 \mathrm{MPa} \cdot \mathrm{m}^{1 / 2}$.

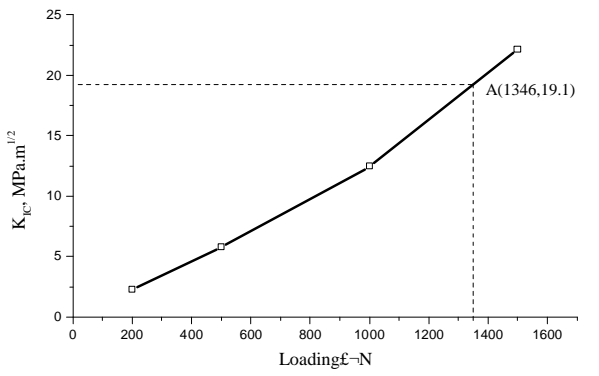

Fig.8 Stress intensity factor at crack tip \& loading in Be specimen

\section{Conclusions}

( 1 ) The stress distribution for beryllium compact tension specimen is acquired by FEM and X-ray stress measurement, which is tension stress near crack tip and compression stress far from crack tip $(>5 \mathrm{~mm})$. The stress value and the stress concentration increases with increasing the loading.

(2) At critical loading, the maxium plastic strain at crack tip in Be specimen is about $0.018 \mu \varepsilon$ and the maxium radius of plastic zone is about $0.3 \mathrm{~mm}$.

(3) Combined experiment and FEM togther, the fracture toughness of Be with plane strain state is determined indirectly, which is about $19.1 \mathrm{MPa} \cdot \mathrm{m}^{1 / 2}$.

\section{Acknowledgements}

This work was performed with support of the key Sci. \& Tech. Found of China Academy of Engineering Physics (Contract No. 2005Z0302). 
2001,10(1):59 62

[3] Zhang Pengcheng. Study of eliminating machine damage in Be[J]. Nonferrous metal, 2001,53(1): 60 63

[4] Dong Ping, Chen YZ, Zou JS. Numerical simulation on laser beam braze welding of beryllium ring[J]. Acta metallurgica sinica, 2002,38 (8): 881-884

[5] Dong Ping, Chen YZ, Zou JS. Comparison of axisymmetric and 3-D thermal elastic-plastic analytical models for beryllium welding[J]. Rare metal materials and engineerin, 2004,33(6):585-588

[6] Dong Ping, Chen YZ, Bai CM. Measurement of X-ray stress constant of beryllium[J]. Rare metal materials and engineering, 2004, 33 (4): 445-448 